\title{
R-CURVE BEHAVIOR AND CRACK PROPAGATION PROPERTIES OF ASPHALT CONCRETE AT LOW TEMPERATURES
}

\author{
Sepehr GHAFARI, Fereidoon MOGHADAS NEJAD \\ Department of Civil \& Environmental Engineering, Amirkabir University of Technology, Tehran 15875, Iran
}

Received 02 Aug 2012; accepted 05 Nov 2012

\begin{abstract}
Fracture properties and crack propagation characteristics of asphalt concrete mixtures were studied by obtaining fracture resistance curves using three point single edge $\mathrm{SE}(\mathrm{B})$ notched beam specimens. Elastic-plastic approach is used in the calculation of the J-integral since the fracture process zone size is large enough to not use a linear elastic approach. Crack length measurements were obtained directly from high resolution images taken during the tests. A rising R-curve was observed in all the specimens which indicates ductility and a toughening mechanism in the ductile to quasi-brittle fracture of the mixture. Mixtures developed by limestone and siliceous aggregates with $4 \%, 4.5 \%$ and $5 \%$ binder contents were tested at temperatures ranging from $+5^{\circ} \mathrm{C}$ to $-20^{\circ} \mathrm{C}$. Mixtures with $5 \%$ binder content showed greater crack resistant behavior at each temperature. Crack lengths at which crack propagation instability occurred were decreased by the reduction of temperature. A significant drop of this critical crack length is observed in temperatures below $-15^{\circ} \mathrm{C}$. As well, the elastic-plastic fracture toughness is increased by the reduction of temperature up to $-15^{\circ} \mathrm{C}$ and starts to diminish thereafter.
\end{abstract}

Keywords: resistance curves, unloading compliance, fracture toughness, stable crack growth.

\section{Introduction}

Low-temperature cracking of Hot Mix Asphalt (HMA) has been a serious concern for pavement engineers during years. Experience has shown that even though the effect of these non-loading cracks on the transportation quality may be negligible at the initial stages, but infiltration of water into the cracks, as well as reduction of the structural integrity and the load bearing capacity of the pavement in the cracked zones which cause the propagation of the initial cracks and further damage to the pavement, lead to a considerable deterioration of the pavement structure during its performance period.

Studying the behavior of HMA at low temperatures from a fracture mechanics point of view has received substantial attention in the past decade. Various test methods have been used by researchers to investigate fracture properties of asphalt concrete mixtures. Braham et al. (2007) studied the effect of binder type, aggregate, and mixture composition on the fracture energy of HMA at low temperatures by means of disc-shaped compact tension tests, DC(T). Wagoner et al. (2005) compared different test methods and developed a fracture test procedure based on the three point single edge notched bend, $\mathrm{SE}(\mathrm{B})$, configuration. It was concluded in their work that the $\mathrm{SE}(\mathrm{B})$ provides the most promising method for evaluating fracture properties of asphalt concrete mixtures due to its capability for pure mode I loading, test simplicity, and amendable stress states (simple stress fields, minimal end effects, etc.). Examples of the use of SE(B) test can also be seen in the works done by Reis et al. (2011) for studying fracture properties of PET modified asphalt. Dongre et al. (1989), implemented low temperature testing on single edge notched bend $\mathrm{SE}(\mathrm{B})$ specimens with varying binder properties. Linear elastic fracture mechanics approach (LEFM) was used to obtain the mode I fracture toughness, $\mathrm{K}_{\mathrm{IC}}$. A procedure to estimate the approximate elastic-plastic critical strain release rate, $\mathrm{J}_{\mathrm{C}}$, was also implemented. The two toughness quantities were compared and it was shown that the $\mathrm{J}_{\mathrm{C}}$ is a more realistic fracture characterization approach.

In a research by Kim and El Hussein (1997), low temperature fracture toughness values were obtained experimentally for asphalt concrete based on nonlinear elastic relations using lime and granite aggregates and different conditioning scenarios. Their results showed that the fracture toughness variations followed analogous trends for both aggregate types and conditioning scenarios. $\mathrm{K}_{\mathrm{IC}}$ exhibited an increase from $-5^{\circ} \mathrm{C}$ to $-15^{\circ} \mathrm{C}$ and then reduced to $-30{ }^{\circ} \mathrm{C}$. Both the increase and the reduction in $\mathrm{K}_{\mathrm{IC}}$ were concluded to be results of mechanical adhesion variations of the binder and aggregate matrix in the mixture. 
The unloading compliance approach and the R-curve concept has been employed (Mobasher, Mamlouk 1997) based on the non-linear fracture mechanics to evaluate the crack propagation properties of conventional and asphalt rubber mixtures. The energy release rate was obtained to account for the inelastic effects. A total stress intensity factor was calculated and the crack length at successive intervals of crack growth was computed by means of an unloading compliance process which consisted of using a compliance equation proposed principally for concrete. Variations of the $\mathrm{K}_{\mathrm{IC}}$ with percent binder content and temperature were compared and evaluated. Tests were conducted at two temperature levels of $-1{ }^{\circ} \mathrm{C}$ and $-7^{\circ} \mathrm{C}$. It was concluded that the fracture toughness of the mixtures increased by increasing the binder content.

Marasteanu et al. (2002), assumed the validity of the LEFM concept for asphalt concrete due to the sufficiently large specimen size they used in the SE(B) specimens and conducted fracture toughness tests based on ASTM E399-09 (2009) to obtain the linear elastic planestrain fracture toughness, $\mathrm{K}_{\mathrm{IC}}$, of asphalt mixtures at low temperatures. They applied the compliance method suggested in ASTM E399-09 (2009) for metallic materials to calculate the crack length and obtained the K-R curves. Results showed that the linear elastic fracture toughness is increased by the crack length and that the mixture exhibited more nonlinear behavior in $-18{ }^{\circ} \mathrm{C}$ than in $-34^{\circ} \mathrm{C}$.

Li and Marasteanu (2010), reported a relatively large size of the fracture process zone (FPZ) in their investigations on semi-circular bend ( $\mathrm{SCB}$ ) samples of asphalt concrete mixtures at low temperatures which further necessitates the fracture analysis of asphalt mixture with elastic-plastic fracture mechanics (EPFM).

The J-integral proposed by Rice (1968), has been a widely used elastic-plastic fracture parameter for describing stresses and the intensity of the HRR field around the crack tip. J-R curves, as the most important material property in EPFM analysis, is an illustration of the resistance of a material to crack propagation (Zhu, Joyce 2009).

The resistance curve is also used to predict conditions necessary for unstable crack growth through the material (Anderson 2005). Determination of J-R curves requires the crack length to be known. Hence, the crack length must be monitored during the test. The multiple specimen test procedure, in which the crack length is measured visually on the fracture surface has been a common test protocol. However, this procedure needs a considerable number of specimens to be developed and tested for obtaining a J-R curve. As well, in ASTM E1820-09 (2009), this method is valid only if the fracture initiation toughness is to be determined. In order to be able to obtain a full-range J-R curve, two single specimen techniques were developed in which the crack lengths are either monitored by the electrical potential drop or the elastic compliance (Zhu, Joyce 2012). The latter technique is not applicable to asphalt concrete mixtures since the material is not an electrical conductor.
The unloading compliance method is widely used in J-R curve testing of metals; nevertheless, techniques such as the normalization method for obtaining crack lengths have also shown close agreements with the unloading compliance method (Zhu, Joyce (2007). However, since the unloading compliance method cannot be used for materials that do not exhibit a perfectly linear-elastic behavior in loading (Zhu, Joyce 2012) and due to the non-homogenous nature of the asphalt mixture as well as its hysteretic behavior in loading/unloading cycles, obtaining crack extensions by the above mentioned method may not be reliable.

It can be observed from the above that a majority of fracture mechanics researches on asphalt concrete mixtures so far have been focusing on obtaining (mostly elastic) fracture criteria such as toughness values, fracture energy, etc. However, in order to better assess the low temperature fracture failure mechanisms as well as the preventive measures in asphalt concrete, a detailed knowledge of asphalt resistance to crack growth is essential.

Due to lack of available information about the trend of crack growth in asphalt concrete mixtures and in order to be able to design mixtures with satisfactory fracture properties, in this research, mode I elastic-plastic crack propagation regime of asphalt concrete at low temperatures are studied by means of the resistance curves.

In this research, a single specimen technique is used for an elastic-plastic fracture resistance analysis of the asphalt concrete mixtures. The $\mathrm{SE}(\mathrm{B})$ test is used for fracture analysis of asphalt concrete in this research based on its advantage over other configurations (Wagoner et al. 2005). Actual crack extensions during the test are measured from the images taken by high resolution digital cameras during the test to assure the accuracy of the results. This process can be a suitable alternative for the unloading compliance method and the compliance equations for obtaining increments of crack extension since the hysteretic effects and inelasticity of the asphalt concrete mixture bring about inaccuracies in crack length calculations. In order to obtain more accurate results, and due to uncertainties and overestimations resulted in the load-line displacement based J-integral calculations, a crack mouth opening displacement (CMOD) based J-integral is described and used. In addition to the determination of the values of the elastic plastic fracture initiation toughness $\left(\mathrm{J}_{\mathrm{IC}}\right)$ using the Resistance curves, critical crack lengths initiating unstable crack propagation are also obtained along with the corresponding value of the J-integral at the onset of unstable crack growth.

\section{Materials and methods}

\subsection{Specimen preparation}

Mixtures with limestone (A) and siliceous aggregates (B) having three different binder contents of $4 \%, 4.5 \%$, and $5 \%$ were developed in this research. Physical properties of the aggregates are summarized in Table 1 . The ag- 
gregate gradation used for the mixtures is selected according to the local code (Iran highway asphalt paving code 2011) and depicted in Figure 1. The allowable upper and lower bounds are shown as the two thick curves. AC 85/100 penetration grade (PG 58-22) bitumen was used in the mixtures. Marshall mix design procedure was followed and an optimum binder content of $4.5 \%$ was obtained for mixtures with limestone and 5.4\% for mixtures with siliceous aggregates.

Table 1. Physical properties of the aggregates

\begin{tabular}{|c|c|c|c|}
\hline \multirow{2}{*}{ Test } & \multirow[t]{2}{*}{ Standard } & $\begin{array}{c}\text { Limestone } \\
\text { aggregates (A) }\end{array}$ & $\begin{array}{c}\text { Siliceous } \\
\text { aggregates (B) }\end{array}$ \\
\hline & & Value $(\%)$ & Value $(\%)$ \\
\hline $\begin{array}{l}\text { LA } \\
\text { abrasion } \\
\text { loss }\end{array}$ & $\begin{array}{c}\text { AASHTO } \\
\text { T96-02 } \\
(2002)\end{array}$ & 20.5 & 19 \\
\hline $\begin{array}{l}\text { Crushed in } \\
\text { one face }\end{array}$ & $\begin{array}{c}\text { ASTM } \\
\text { D5821-13 } \\
(2013)\end{array}$ & $>98$ & $>87$ \\
\hline $\begin{array}{l}\text { Crushed in } \\
\text { two faces }\end{array}$ & $\begin{array}{c}\text { ASTM } \\
\text { D5821-13 } \\
(2013)\end{array}$ & $>98$ & 93 \\
\hline Flakiness & $\begin{array}{c}\text { BS } 812-103.1 \\
(1985)\end{array}$ & 5 & 20 \\
\hline $\begin{array}{l}\text { Coating of } \\
\text { aggregate }\end{array}$ & $\begin{array}{c}\text { AASHTO } \\
\text { T182-84 } \\
(2002)\end{array}$ & 98 & 95 \\
\hline $\begin{array}{l}\text { Sodium } \\
\text { Sulphate } \\
\text { loss }\end{array}$ & $\begin{array}{c}\text { AASHTO } \\
\text { T104-99 } \\
(2003)\end{array}$ & $\begin{array}{c}1.8 \text { (fine) and } \\
0.7 \text { (coarse) }\end{array}$ & $\begin{array}{c}2.8 \text { (fine) and } \\
0.4 \text { (coarse) }\end{array}$ \\
\hline
\end{tabular}

Asphalt beam specimens were obtained from a beam compactor equipment designed according to ASTM D3202-2000 (2000). To eliminate the effects such as aggregate segregation, undesirable density distribution, etc., the beams were cut using a water cooled automated-saw to the dimensions of $80 \mathrm{~mm}$ tall by $40 \mathrm{~mm}$ wide with a span length of $320 \mathrm{~mm}$. The dimensions are chosen based on the instructions in ASTM E1820-09 (2009) for single edge notched beam dimensions for fracture resistance testing. A mechanical notch with an initial length of $16 \mathrm{~mm}$, resulting in a crack length $(a)$ to width $(w)$ ratio of $0.2(a / w=0.2)$ was fabricated in the middle of the beam span.

Half of the notch length was cut using the water cooled automated saw with a $5 \mathrm{~mm}$-thick blade. The remaining notch length was then cut by a $1 \mathrm{~mm}$-thick handsaw to mitigate blunting of the notch at the tip as suggested by Wagoner et al. (2005).The asphalt beam and the fabricated mechanical notch are shown schematically in Figure 2. The two specimen faces were painted in white using a water based paint to enhance crack propagation tracking while processing the images taken continuously during the test. Measurement scales with a precision of $1 \mathrm{~mm}$ were stuck to both faces of the beams for measuring the crack length.

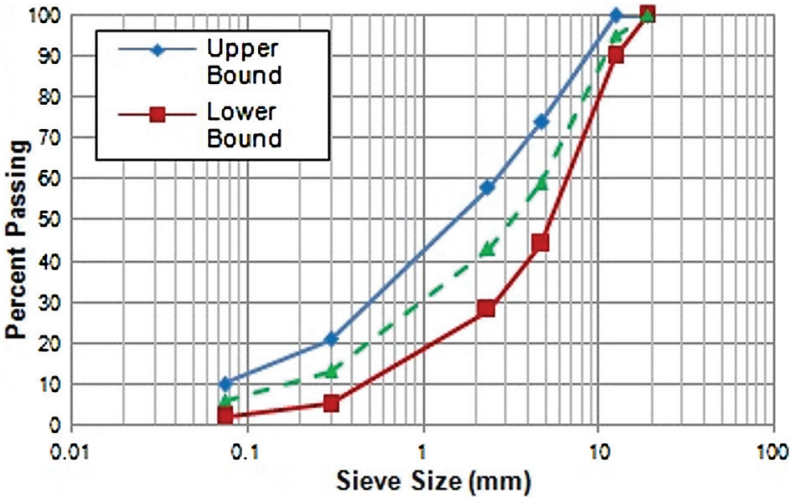

Fig. 1. Aggregate Gradation used in the asphalt mixtures

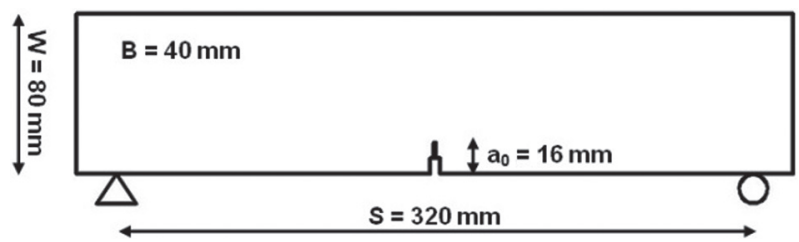

Fig. 2. Schematic of the asphalt beam and the fabricated mechanical notch dimensions

\section{2. $\mathrm{SE}(\mathrm{B})$ test procedure}

The test is conducted under a three point bending configuration. The ASTM E1820-09 (2009) specifications for the loading fixture are used in the test setup. The fixture was developed with a span length of $320 \mathrm{~mm}$ and a width of $100 \mathrm{~mm}$. The rollers have a diameter of $40 \mathrm{~mm}$ and are setup to be free in rotation and moving apart slightly but are positioned to have the initial span length of $320 \mathrm{~mm}$ using soft springs. The center load point designed to provide a uniform loading has a radius of $10 \mathrm{~mm}$ which is equal to w/8 (ASTM E1820-09 2009).

The three point bend tests were carried out using a universal testing machine equipped with an environmental chamber with a total loading capacity of $25 \mathrm{kN}$. The load-line displacements and the compressive load on the beam surface are collected by the LVDT at the load frame actuator. A clip gauge was developed according to ASTM E1820-09 (2009) to separately measure the values of crack mouth opening displacements during the test. Asphalt beams were placed in the environmental chamber of the testing machine 4 hours before the beginning of the test to confide the uniformity of temperature distribution throughout the specimens. Before starting the test, a preload ( $0.1 \mathrm{kN}$ in most cases) was applied to the beam to assure its being seated on the fixture. Two high resolution digital cameras were mounted focusing on the two faces of the beam to continuously take pictures during the test with intervals of 5 and 1 seconds. A computer code was developed to synchronize the images taken continuously during the test with the corresponding values of load, load-line displacement and crack mouth opening displacements. Crack length increments during the test were measured directly from the high resolution 
images of both specimen faces using the open source image processing software Imagej. Crack length values used in the J-R curve calculations were average values taken by the two cameras at specific time steps allowing a single specimen J-R testing process to be carried out. The test setup is shown in Figure 3. Mixtures with limestone and siliceous aggregates having three binder contents of $4 \%, 4.5 \%$, and $5 \%$, were tested in 6 temperature levels of $+5,0,-5,-10,-15$, and $-20^{\circ} \mathrm{C}$. Three test replicates were made for each experiment. Figure 4 illustrates three typical stages of captured crack growth in a test.

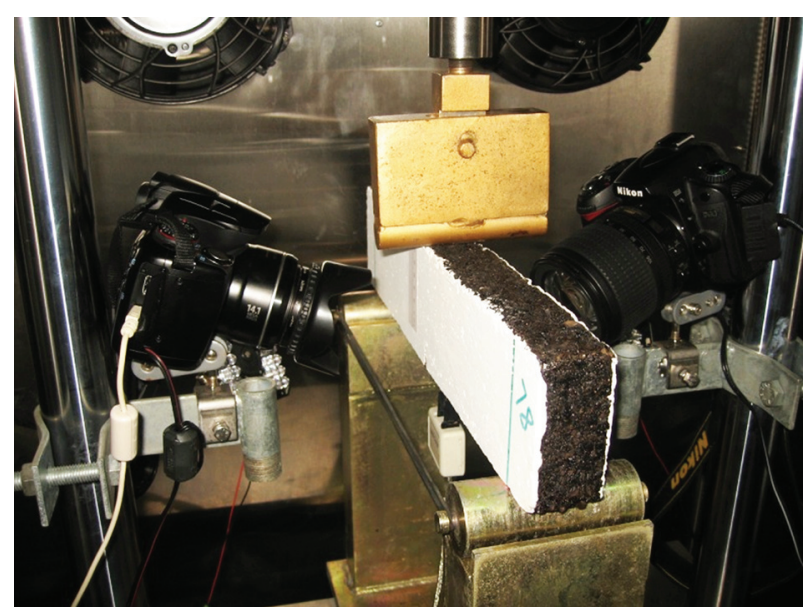

Fig. 3. SE(B) test setup
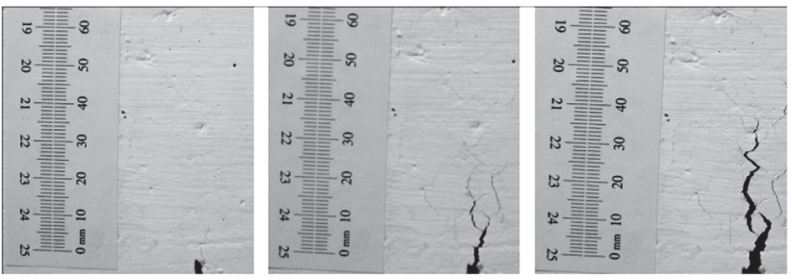

Fig. 4. Three exemplary stages of crack advance during the test

\subsection{Dynamic modulus tests}

Compressive dynamic modulus testing of the mixtures was carried out according to ASTM D3497-79(2003) (2003) with $0.1 \mathrm{~Hz}$ to $20 \mathrm{~Hz}$ loading frequencies. Cylindrical specimens with a height of $150 \mathrm{~mm}$ and a diameter of $100 \mathrm{~mm}$ were prepared. LVDT holders were glued to the specimen and the axial LVDTs were then mounted on them. Figure 5 shows the dynamic modulus test setup. Tests were run at six temperature levels of $+5,0,-5,-10$, -15 , and $-20{ }^{\circ} \mathrm{C}$. A typical loading wave and response which is based on a maximum axial stress of $241 \mathrm{kPa}$ is depicted in Figure 6. Elastic moduli obtained from the dynamic modulus tests explained above are presented in Table 2 and used in the calculations of the J-integral. Table 3 lists a summary of the experiments for the present research.
Table 2. Elastic moduli (MPa) obtained from the dynamic modulus tests

\begin{tabular}{|c|c|c|c|c|c|c|c|}
\hline \multirow{2}{*}{\multicolumn{2}{|c|}{$\begin{array}{c}\text { Mixture } \\
\% \text { Binder } \\
\text { Content }\end{array}$}} & \multicolumn{3}{|c|}{ A } & \multicolumn{3}{|c|}{ B } \\
\hline & & $4 \%$ & $4.5 \%$ & $5 \%$ & $4 \%$ & $4.5 \%$ & $5 \%$ \\
\hline \multirow{6}{*}{ 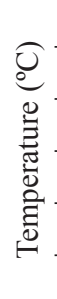 } & 5 & 3065 & 4743 & 3383 & 2186 & 2241 & 2810 \\
\hline & 0 & 4159 & 5273 & 4862 & 2695 & 2726 & 4076 \\
\hline & -5 & 4817 & 8131 & 5430 & 3155 & 3611 & 5010 \\
\hline & -10 & 5712 & 11108 & 6956 & 4159 & 4557 & 6579 \\
\hline & -15 & 6814 & 15740 & 8384 & 4945 & 5503 & 8022 \\
\hline & -20 & 7534 & 19082 & 10248 & 6673 & 8047 & 9381 \\
\hline
\end{tabular}

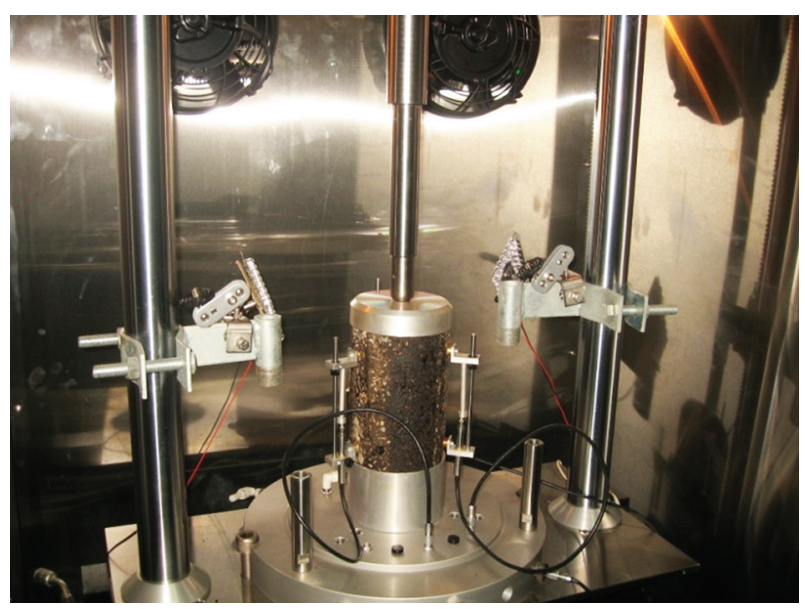

Fig. 5. Dynamic modulus test setup
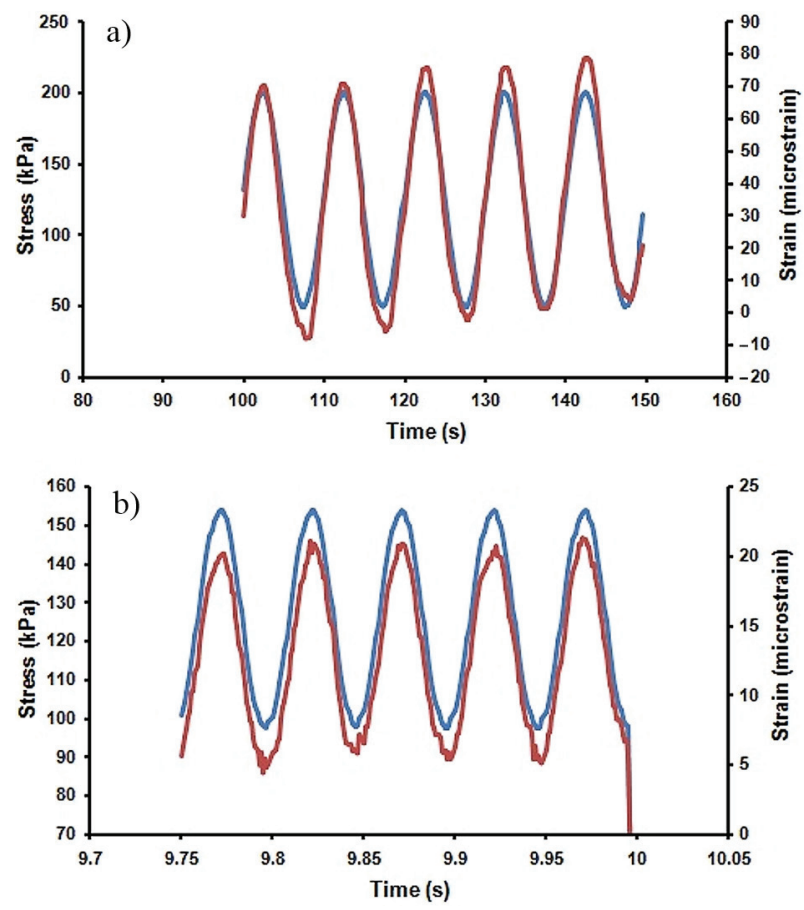

Fig. 6. Dynamic modulus loading: a) Haversine loading of the cylindrical specimen at a frequency of $0.1 \mathrm{~Hz}$ and the associated response; b) Haversine loading of the cylindrical specimen at a frequency of $20 \mathrm{~Hz}$ and the associated response 
Table 3. Scope of the experiments

\begin{tabular}{cccc}
\hline Mixture & A and B & A and B & A and B \\
\hline $\begin{array}{c}\text { \% Binder } \\
\text { Content }\end{array}$ & $4 \%$ & $4.5 \%$ & $5 \%$ \\
\hline \multirow{4}{*}{$\begin{array}{c}\text { Temperature } \\
\left({ }^{\circ} \mathrm{C}\right)\end{array}$} & 5 & 5 & 5 \\
& -10 & 0 & 0 \\
& -15 & -10 & -5 \\
& -20 & -15 & -15 \\
& - Dynamic & - Dynamic & - Dynamic \\
Tests & Modulus & Modulus & Modulus \\
& (3 replicates) & (3 replicates) & (3 replicates) \\
\cline { 2 - 4 } & - SE(B) & - SE(B) & - SE(B) \\
& (3 replicates) & (3 replicates) & (3 replicates) \\
\hline
\end{tabular}

\subsection{J-integral calculation}

As pointed out earlier, Rice (1968), proposed the $\mathrm{J}$-integral for a nonlinear elastic material as a measure of the crack tip singularity amplitude of the HRR field. J-integral was for the first time evaluated experimentally by Begley and Landes (1972) and Landes and Begley (1972) based on its energy release rate definition, expressed as in Eqn (1):

$$
J=-\frac{d U}{B d a},
$$

where $U$ is the strain energy and $B$ is the specimen thickness. The term "rate" addresses the change in the strain energy by each increment of crack growth, $d a$. Rice (1968) presented experimentally measurable forms of $J$ as in Eqn (2):

$$
\begin{gathered}
J=\frac{1}{B} \int_{0}^{P} \frac{\partial \Delta}{\partial a} d P ; \\
J=-\frac{1}{B} \int_{0}^{\Delta} \frac{\partial P}{\partial a} d \Delta,
\end{gathered}
$$

where $P$ is the load and $\Delta$ is the load line displacement (LLD).

Considering the fact that $\Delta$ is composed of elastic, $\Delta_{e l}$, and plastic, $\Delta_{p l}$ components for an elastic-plastic material, $J$ can be written as:

$$
J=J_{e l}+J_{p l},
$$

where the elastic $J$ can be computed using the stress intensity factor, K. Hence, for plain strain configurations, according to ASTM E1820-09 (2009), $J_{e l}$ is calculated by Eqn (4):

$$
J_{e l}=\frac{K^{2}\left(1-v^{2}\right)}{E},
$$

where: $E$ - The Young's modulus, and u - Poisson's ratio.

The plastic $J$ is then determined by Eqns (2a) and (2b) as follows in Eqn (5):

$$
J_{p l}=\frac{1}{B} \int_{0}^{P} \frac{\partial \Delta_{p l}}{\partial a} d P=-\frac{1}{B} \int_{0}^{\Delta_{p l}} \frac{\partial P}{\partial a} d \Delta_{p l}=\frac{\eta_{L L D} A_{L L D}^{p l}}{b B},
$$

where $A_{L L D}^{p l}$ is the plastic fraction of the area under the $P-\Delta$ curve.

Knowing that the $J$ obtained by the expressed method is for a stationary crack, the $J$ estimations should be corrected at any increment of crack extension to account for a growing crack condition. Based on the deformation theory of elasticity, Ernst et al. (1981) derived the complete differential of $J_{p l}$ as in Eqn (6):

$$
d J_{p l}=\frac{\eta_{L L D} P}{b B} d \Delta_{p l}-\frac{\gamma_{L L D}}{b} J_{p l} d a,
$$

where $\eta_{L L D}$ and $\gamma_{L L D}$ are geometry factors depending on the $a / w$ ratio. Integrating Eqn (6) to find $J$ yields:

$$
J_{p l}=\int_{0}^{\Delta_{p l}} \frac{\eta_{L L D} P}{b B} d \Delta_{p l}-\int_{a_{0}}^{a} \frac{\gamma_{L L D}}{b} J_{p l} d a .
$$

Applying a numerical method of incremental integration to compute $J_{p l}$, for a crack extending from $a_{i}$ to $a_{i+1}$ corresponding to plastic LLDs of $\Delta_{p l}^{i}$ and $\Delta_{p l}^{i+1}$ respectively, the LLD based incremental J-integral equation will be as follows:

$$
J_{p l(i+1)}=\left(J_{p l(i)}+\frac{\eta_{L L D}^{i}}{b_{i} B} A_{\Delta p l}^{i+1}\right)\left(1-\frac{\gamma_{L L D}^{i}}{b_{i}}\left(a_{i+1}-a_{i}\right)\right) .
$$

Zhu et al. (2008) proposed a CMOD based J-integral calculation method to enhance the accuracy of J-integral calculations in comparison with the LLD based $J$ values especially for shallow-cracked $\mathrm{SE}(\mathrm{B})$ specimens which is the case in the present research. They followed a procedure similar to that of the LLD based $J$ computation and formulated a CMOD based $J$ estimation scheme.

The total CMOD, denoted by $V$, is separated into an elastic component, $V_{e l}$, that can be calculated at any load point by load times the elastic CMOD compliance; and a plastic one, $V_{p l}$. Obtaining the plastic $J$ for a stationary crack and applying corrections for the growing crack condition one has:

$$
J_{p l}=\int_{0}^{V_{p l}} \frac{\eta_{C M O D} P}{b B} d V_{p l}-\int_{a_{0}}^{a} \frac{\gamma_{C M O D}}{b} J_{p l} d a,
$$

where $\eta_{C M O D}$ and $\gamma_{C M O D}$ are the CMOD based geometry factors and $b$ is the remaining ligament.

By means of a numerical integration procedure, the CMOD based incremental J-integral equation for a growing crack is obtained as the following:

$J_{p l(i+1)}=\left(J_{p l(i)}+\frac{\eta_{C M O D}^{i}}{b_{i} B} A_{V p l}^{i+1, i}\right)\left(1-\frac{\gamma_{C M O D}^{i}}{b_{i}}\left(a_{i+1}-a_{i}\right)\right)$.

$\eta_{C M O D}$ is updated at every increment of crack length using equation 11 which is concluded to be the most accurate by Zhu et al. (2008):

$$
\eta_{C M O D}=3.667-2.199(a / w)+0.437(a / w)^{2} .
$$

Similarly, the incrementally updated Eqn (12) is used for $\gamma_{C M O D}$ :

$$
\gamma_{C M O D}=0.131+2.131(a / w)-1.465(a / w)^{2} .
$$


It should be noted that the geometry factors, $\eta$ and $\gamma$, computed by Eqns (11) and (12), are obtained for metals. Even though they are used in their current form in the present research, they can be calibrated using finite element analyses for asphalt concrete to improve the accuracy of the analysis.

In order to reduce uncertainties of the LLD based J-integral calculations resulted mainly from slightly inaccurate LLD readings of the actuator LVDT (the contact area between the top surface of the asphalt beam and the loading roller usually undergoes some degree of crushing which can reduce the accuracy of deflection readings by the LVDT), a CMOD based J-integral calculation described above is used in the present research to obtain more reliable results.

\section{Results and discussions}

\subsection{Temperature}

Typical plots of load vs. LLD and load vs. CMOD for different test temperatures (T) are depicted in Figures $7 \mathrm{a}$ and $7 \mathrm{~b}$. It can be seen that by reducing the temperature, less plastic deformation is encountered in the mixture and the mixture behaves in a more brittle manner. As will be pointed out later, a fracture toughness $\left(\mathrm{J}_{\mathrm{IC}}\right)$ tran-
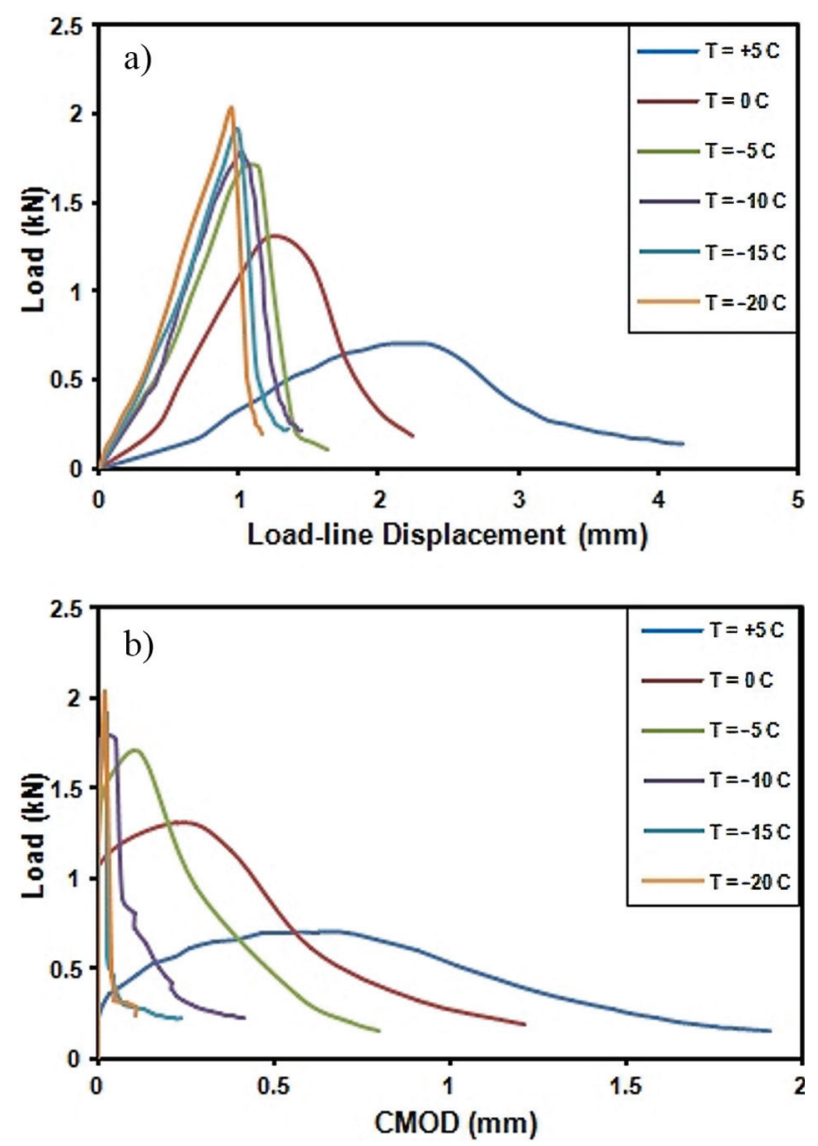

Fig. 7. Load vs. displacement: a) Variations of load vs. LLD at different test temperatures (limestone asphalt concrete with $4.5 \%$ binder content); b) Variations of load vs. CMOD at different test temperatures (limestone asphalt concrete with $4.5 \%$ binder content) sition temperature in which the mixture starts to behave in an entirely brittle manner is found to be in the range of $-15^{\circ} \mathrm{C}$ to $-20^{\circ} \mathrm{C}$ where the ductility of the mixture is significantly diminished and therefore, the behavior cannot be efficiently analyzed by means of the R-curves. This temperature is different from the glass transition temperature $\left(\mathrm{T}_{\mathrm{g}}\right)$ at which the rate of change of specific volume with respect to temperature undergoes a discontinuity. In other words, below the glass transition temperature asphalt concrete is in a glassy state and above that the behavior is viscoelastic (University of Wisconsin-Madison 2010).

From the load versus LLD and load versus CMOD records, it is observed that reduction of temperature leads to a reduced nonlinear and plastic behavior of the mixtures, however, nonlinearity and plastic deformations at lower temperatures are still encountered close to the peak load. This greater nonlinear and plastic deformation trend at higher temperatures causes the greater fracture energy of the mixtures than that at lower temperatures. At lower temperatures, fracture occurs in higher amplitudes of peak load but less displacement (LLD and CMOD). As an example, for a $4 \%$ binder limestone mixture at $+5{ }^{\circ} \mathrm{C}$, the peak load is $0.699 \mathrm{kN}$ and fracture initiates at a load line displacement of $4.161 \mathrm{~mm}$ with a CMOD of 1.907 $\mathrm{mm}$. While for the same mixture tested at $-20{ }^{\circ} \mathrm{C}$, the maximum load at fracture equals $2.020 \mathrm{kN}$ with LLD = $1.163 \mathrm{~mm}$ and CMOD $=0.115 \mathrm{~mm}$. This trend is in agreement with the results of the researches by Kim and El Hussein (1997), Marasteanu et al. (2002), and Braham et al. (2007).

Based on the above, at higher temperatures, greater energy is consumed to form fracture surfaces known as fracture initiation which is mainly due to greater ductility of the binder in the mixture while at lower temperatures and as the ductility of the binder is reduced, less energy is absorbed by the asphalt mixture to experience fracture. As will be discussed in Sections 2.2 and 2.3, a similar trend - i.e. greater susceptibility of the mixtures to unstable crack growth at lower temperatures - is observed for the temperature range considered in this research.

It was also observed that, at higher temperatures (ranging from $+5{ }^{\circ} \mathrm{C}$ to $-10{ }^{\circ} \mathrm{C}$ in this research), fracture initiates and progresses due to the loss of bond between the binder and the aggregates which occurs in the interface of binder and aggregates. As the temperature is reduced and the aggregate-binder bonding is strengthened, fracture can occur in the aggregates if they are in the fracture process zone as indicated in Figure 8.

\subsection{Resistance curve behavior}

\subsubsection{Experimental results of the $J-R$ curves}

As pointed out earlier, test specimens for both aggregate types with three different binder contents of $4 \%, 4.5 \%$, and $5 \%$ were developed in this study. J-Resistance curves for mixtures with limestone aggregates are shown in Figures 9 and 10 depicts resistance curves for mixtures with siliceous aggregates. R-curves are presented based on 


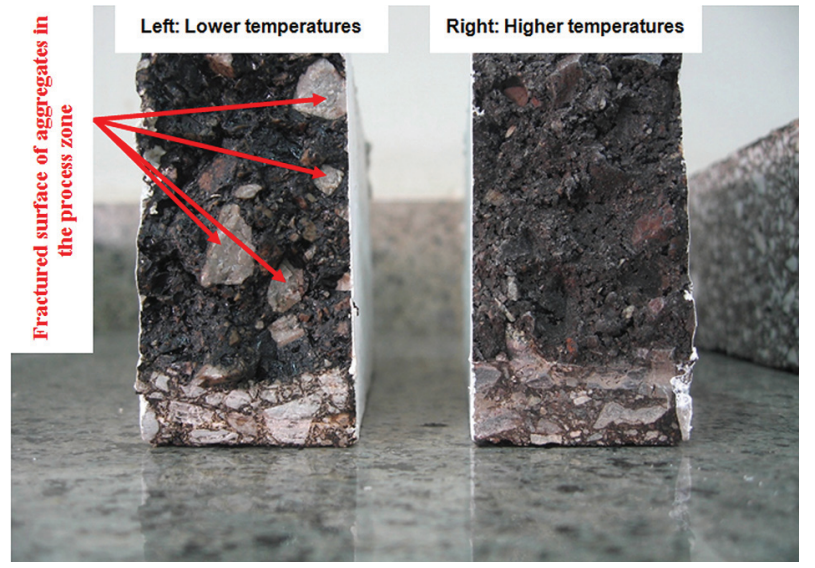

Fig. 8. Fractured aggregates in the specimens tested at lower temperatures (left) vs. fractured binder in specimens tested at higher temperatures (above $-10^{\circ} \mathrm{C}$ )
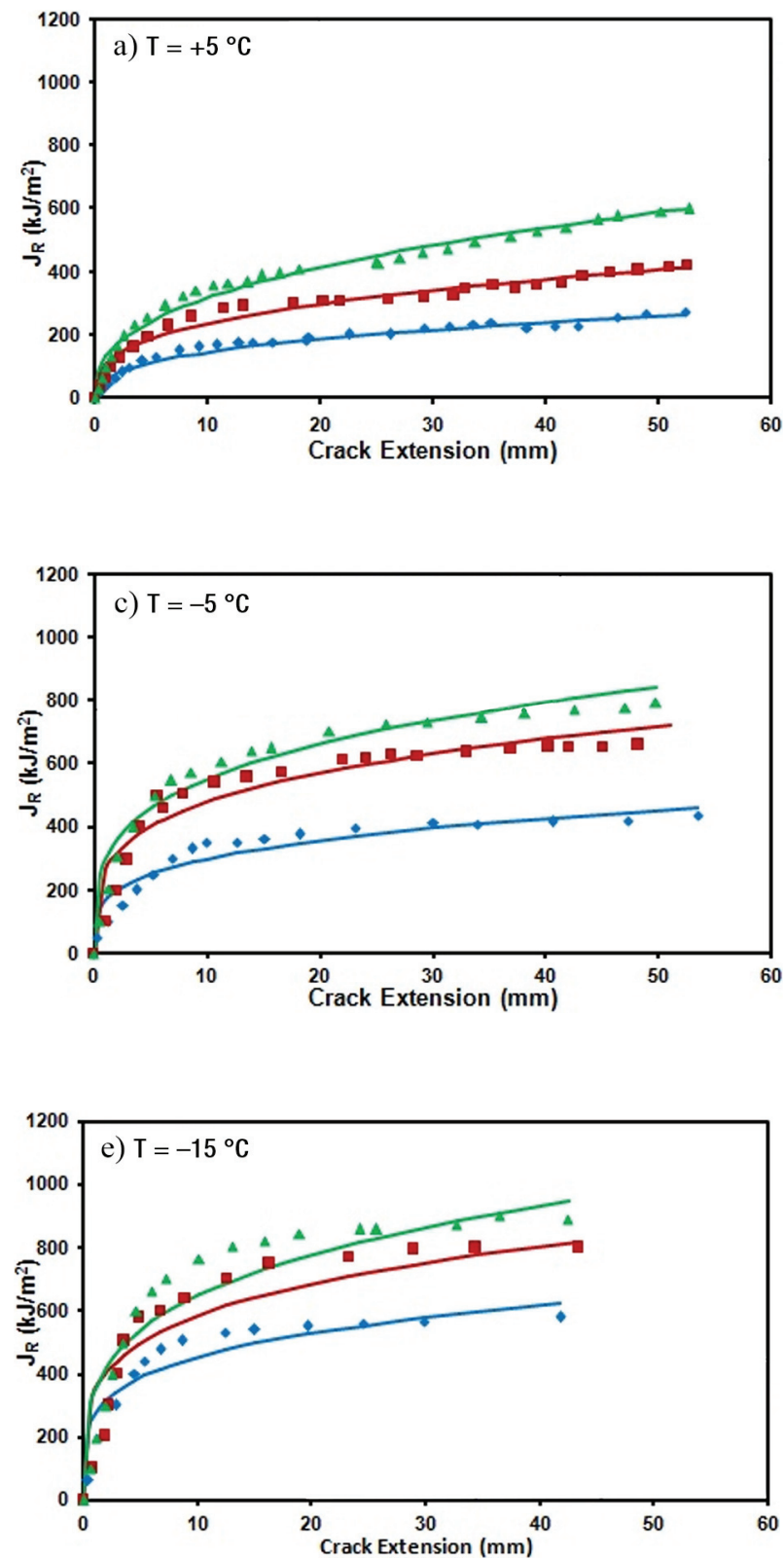

each test temperature, $\mathrm{T}$, which is captioned on top left of each figure. It can be seen that for a specific temperature, increasing the binder content results in a greater fracture resistance of the mixture which is due to the toughening of the mixture caused by increased bonding ability. At lower temperatures, the toughening process persists by reducing the temperature approximately up to the point of the $\mathrm{J}_{\mathrm{IC}}$ transition temperature. By the beginning of the brittle fracture, the mixture exhibits lower fracture resistance and less crack growth stability which is obvious from the flatter R-curves occurred immediately after the vertical state in Figure $9 \mathrm{f}$ and Figure 10f.

It should be noted that, since the low temperature FPZ of the asphalt concrete is reported ( $\mathrm{Li}$, Marasteanu 2010) to have a length of $20 \mathrm{~mm}$ to $25 \mathrm{~mm}$ at a temperature of $-18{ }^{\circ} \mathrm{C}$, crack extension is followed up to a maxi-
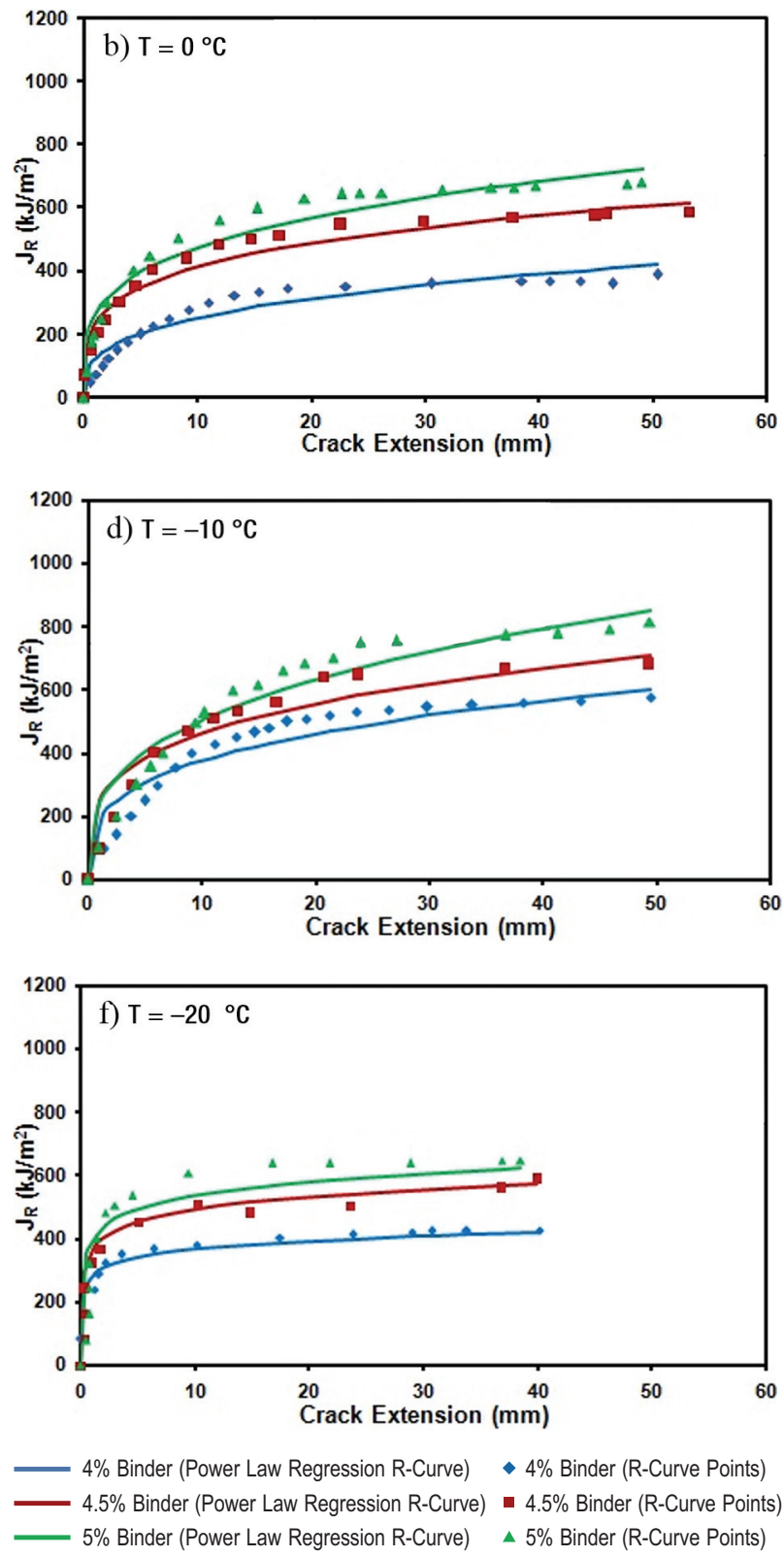

Fig. 9. J-R curves for different test temperatures and binder contents in limestone asphalt concrete 
mum length of $45 \mathrm{~mm}$ at $-15{ }^{\circ} \mathrm{C}$ and $40 \mathrm{~mm}$ at $-20{ }^{\circ} \mathrm{C}$ in this research to assure remaining in the J-controlled region for analysis. However since, to the authors' knowledge, no FPZ lengths are reported for higher temperatures and an extrapolation of FPZ lengths for different temperature levels reported in the same research results in an FPZ length of $15 \mathrm{~mm}$, crack extensions of up to $55 \mathrm{~mm}$ are considered for specimens tested in temperature levels above $-15{ }^{\circ} \mathrm{C}$, to remain in the J-controlled region.

As can be seen in Figures 9 and 10, the R-curve at the initial stages of the crack growth is rising and nearly vertical which is known as the stable crack growth phenomenon. In this stage, even though no apparent crack growth is observed, the J-integral is increasing which is due to the blunting at the crack tip caused by plastic deformations. Later, as the CMOD is increased by further loading the beam specimen, greater apparent crack
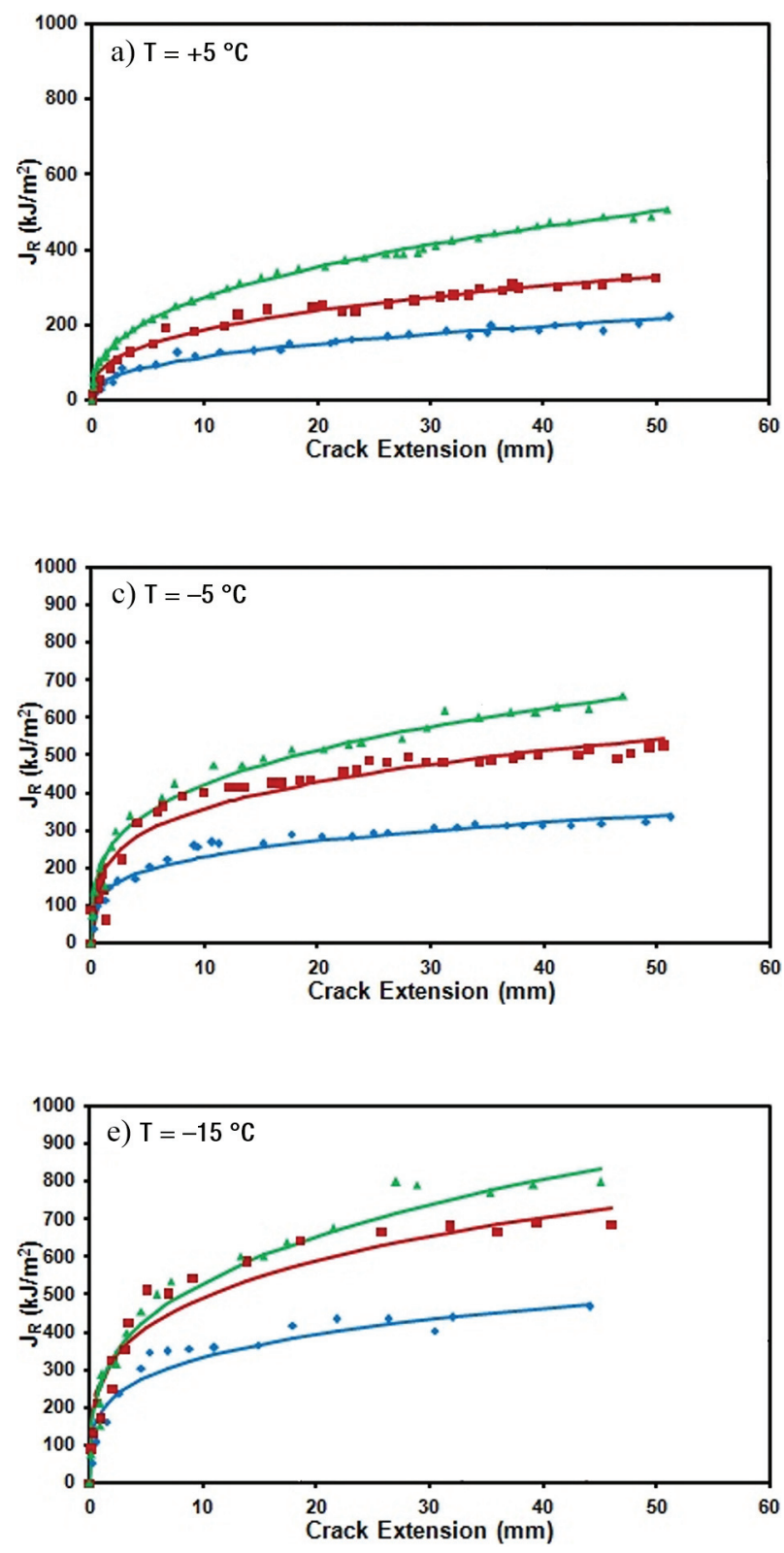

growth is observed (e.g. Figs $4 \mathrm{~b}$ and $4 \mathrm{c}$ ) and the R-curve tends to become less steep which indicates unstable crack growth. This in fact means that further crack propagation in the mixture does not necessarily require an increase in the external load.

R-curves at lower temperatures tend to be steeper or approximately vertical in the initial deformations phase, which is indicative of further brittle behavior of the mixture by reduction of temperature. In the present research, samples tested at $-20{ }^{\circ} \mathrm{C}$ exhibited a dominating brittle behavior and the crack growth was substantially unstable. Figure $9 \mathrm{f}$ indicates a distinct crack growth behavior in comparison with the R-curves obtained for higher test temperatures. At $\mathrm{T}=-20{ }^{\circ} \mathrm{C}$, in less than $3 \mathrm{~mm}$ of crack extension, the R-curve starts to become less steep in such a way that in crack extensions greater than $10 \mathrm{~mm}$, an entirely flat R-curve is encountered. In fact, for a tem-
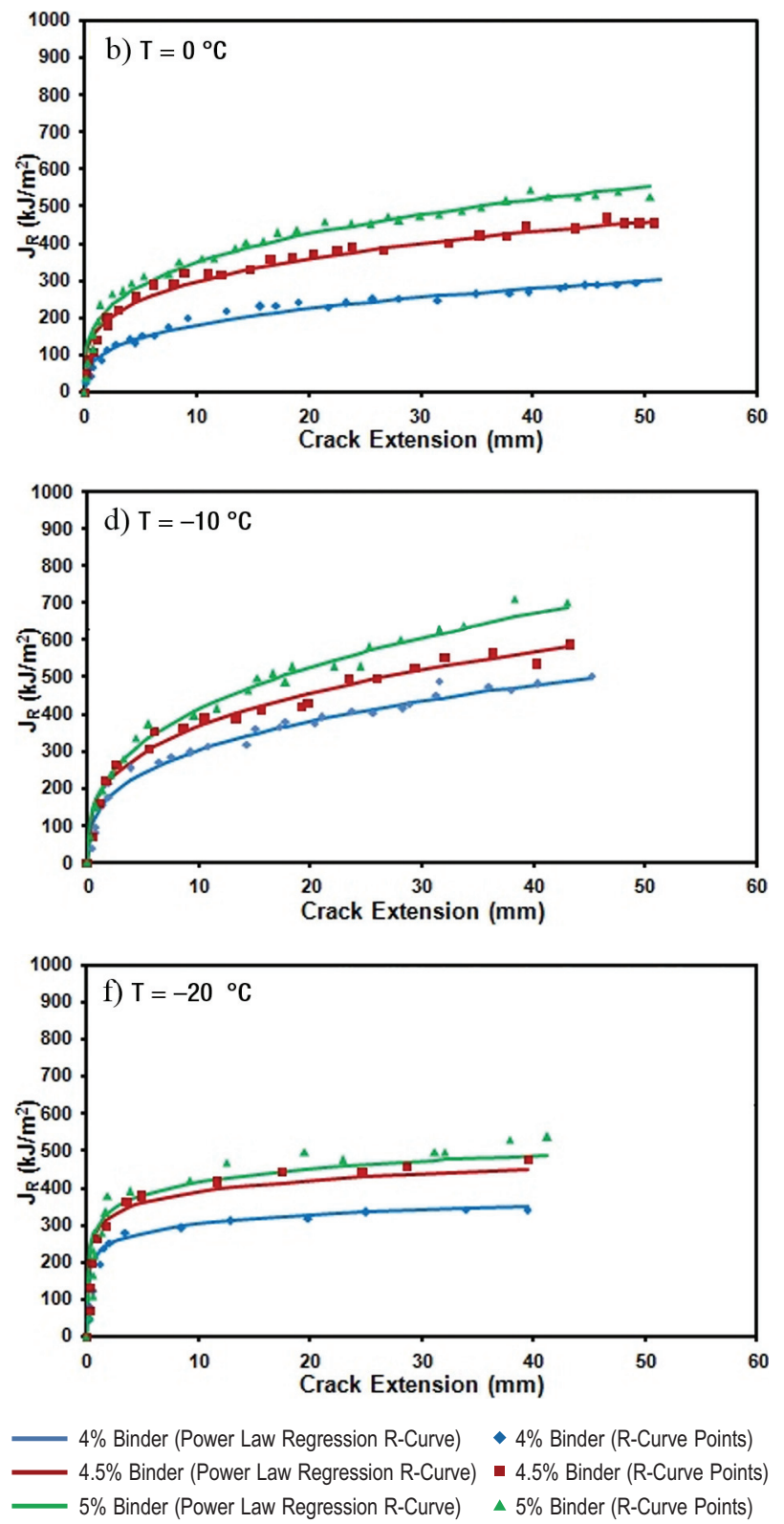

Fig. 10. J-R curves for different test temperatures and binder contents in siliceous asphalt concrete 
perature level of $-20{ }^{\circ} \mathrm{C}$ and below, instability is seen to initiate from very small values of crack extension. The lowest temperature in which the behavior can properly be described and analyzed by the R-curve approach was revealed to lie between $-15{ }^{\circ} \mathrm{C}$ to $-20{ }^{\circ} \mathrm{C}$ in this research that is in close agreement with the findings of Kim and El Hossein (1997) in their non-linear elastic analysis.

\subsubsection{Determination of fracture instability toughness $\left(J_{\text {inst }}\right)$}

All the mixtures tested up to a temperature level of $-15{ }^{\circ} \mathrm{C}$ in this research, have shown an entirely rising $\mathrm{R}$-curve which is a desirable material behavior. However, mixtures with siliceous aggregates have exhibited lower fracture resistance. This is due to the less bond ability between the binder and the aggregates that are a result of less binder coating of siliceous aggregates as presented earlier in Table 1.

J-integral at the onset of instability as well as the crack length required for the initiation of unstable crack growth is measured for the beam specimens. A common methodology which is also used in this study to assess the crack growth instability is generating crack driving force diagrams which is a plot of the applied $\mathrm{J}$ and the $\mathrm{R}$-curve versus crack length.

Figure 11 shows the driving force diagrams for the type A specimens tested at $+5^{\circ} \mathrm{C}$. Instability occurs when the driving force exceeds the resistance of the HMA as indicated in Eqn (11):

$$
\frac{d J_{a p p}}{d a}>\frac{d J_{R}}{d a},
$$

where $J_{a p p}$ is the rate of change in potential energy with the crack area.

Tables 4 and 5, summarize the values of crack lengths initiating unstable crack growth $\left(a_{c r}\right)$ as well as the corresponding value of the J-integral $\left(J_{\text {inst }}\right)$ for each mixture. It is evident from the tables that for a specific test temperature, greater fracture energy is required to initiate unstable crack growth as the binder content is increased. The corresponding values of J-integral at the onset of instability confirm this conclusion. In test temperatures above $-10{ }^{\circ} \mathrm{C}$, as is pointed out earlier, the main reason of failure and instability is the interfacial failure and debonding of aggregates and asphalt binder. Thus, the crack advances through the binder for the most part (referring to Tables 4 and 5, it can be seen that the difference between critical crack lengths for the three binder contents at temperatures above $-10{ }^{\circ} \mathrm{C}$ is considerable). It can be concluded that increasing the binder content leads to a reduction of the critical crack length in the HMA mixtures.

\subsubsection{Determination of fracture initiation toughness $\left(J_{I C}\right)$}

The elastic-plastic fracture toughness $\left(J_{I C}\right)$ defined as the point of the initiation of stable crack growth, is determined by means of the R-curves in this research. Codes such as ASTM E 1820 (2009) and ISO International Standard 12135:2002 (2002) have presented methodolo-
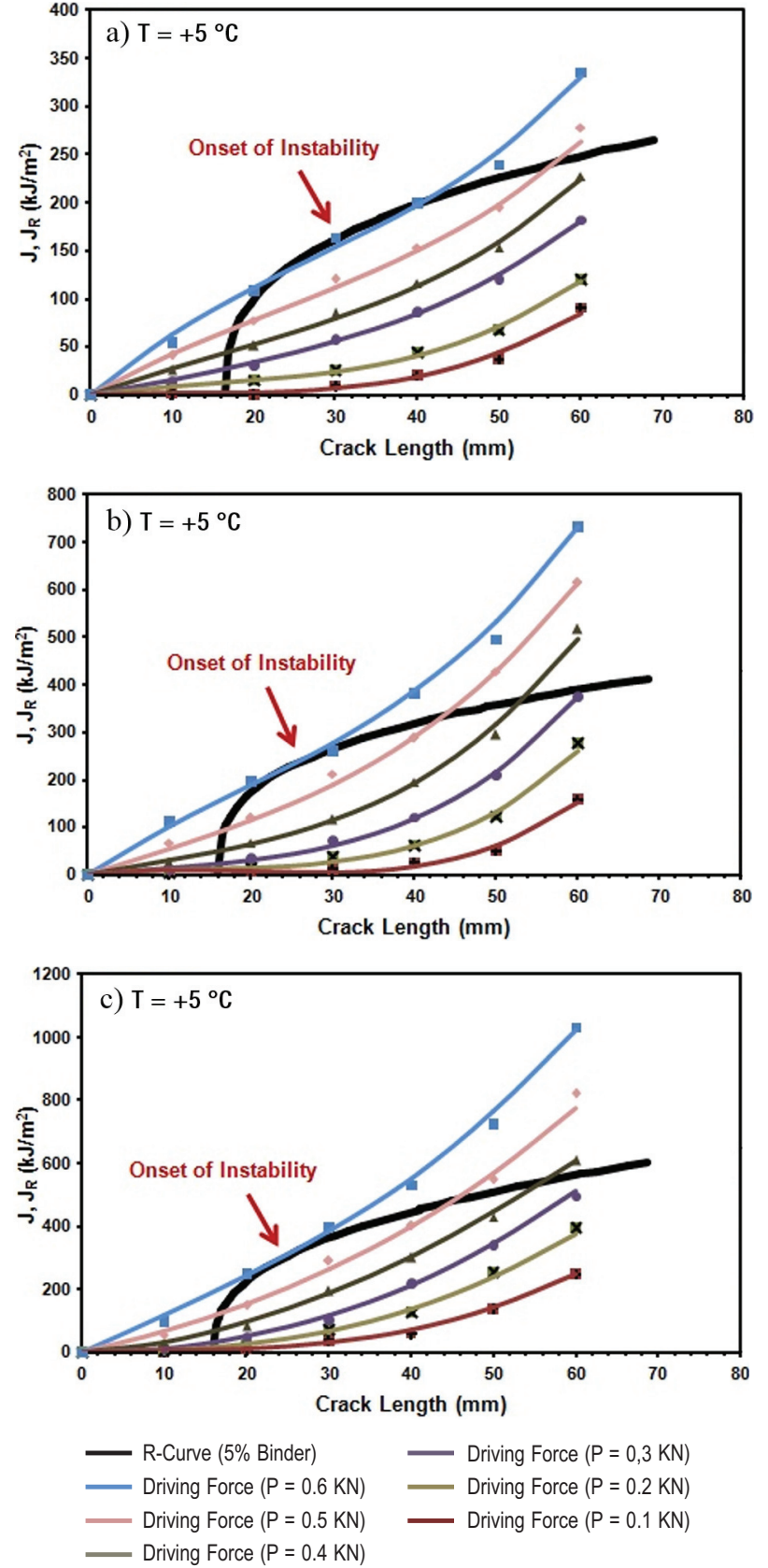

Fig. 11. Driving force vs. the R-curve

gies for the calculation of the $J_{I C}$ in which the fracture initiation toughness is at the point of intersection of the $\mathrm{R}$-curve and the $0.2 \mathrm{~mm}$ offset of the blunting line. In the present research, in order to refrain from the issues in determining a yield strength for asphalt concrete mixtures, the blunting line is constructed based on the ISO methodology in which it is directly related to the ultimate tensile strength $\left(\sigma_{u t s}\right)$ and crack extension, $\Delta a$, (ISO 12135:2002 2002; Landes 2007): $J=3.75 \sigma_{u t s} \Delta a$. Therefore, for a type A mixture with an ultimate tensile strength of $7.52 \mathrm{MPa}$, a binder content of $4 \%$, tested at $+5{ }^{\circ} \mathrm{C}$, the blunting line is expressed as: $J=28.125 \Delta a$. Hence, the $0.2 \mathrm{~mm}$ offset line will be expressed as $J=28.125(\Delta a-0.2)$. Figure 12 depicts the determination of the $J_{I C}$ for the abovementioned mixture. 
Table 4. Fracture toughness and instability initiation J-integral values at six tested temperatures and three binder contents for limestone asphalt concrete

\begin{tabular}{|c|c|c|c|c|c|}
\hline Mixture & $\begin{array}{c}\% \\
\text { Binder }\end{array}$ & $\begin{array}{c}\text { Temp. } \\
\left({ }^{\circ} \mathrm{C}\right)\end{array}$ & $\begin{array}{c}J_{I C} \\
\left(\mathrm{~kJ} / \mathrm{m}^{2}\right)\end{array}$ & $\begin{array}{c}a_{c r} \\
(\mathrm{~mm})\end{array}$ & $\begin{array}{c}J_{\text {instability }} \\
\left(\mathrm{kJ} / \mathrm{m}^{2}\right)\end{array}$ \\
\hline \multirow{18}{*}{ 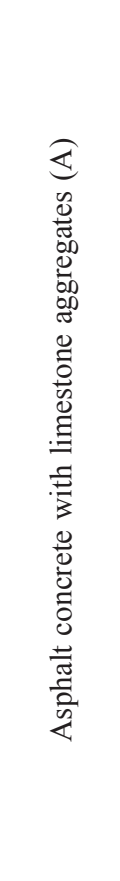 } & \multirow{6}{*}{$4 \%$} & 5 & 56 & 30 & 171 \\
\hline & & 0 & 134 & 24 & 225 \\
\hline & & -5 & 181 & 22 & 254 \\
\hline & & -10 & 223 & 20 & 301 \\
\hline & & -15 & 256 & 19 & 367 \\
\hline & & -20 & 243 & 18.5 & 356 \\
\hline & \multirow{6}{*}{$4.5 \%$} & 5 & 103 & 26 & 263 \\
\hline & & 0 & 285 & 22 & 352 \\
\hline & & -5 & 332 & 20 & 391 \\
\hline & & -10 & 357 & 19 & 377 \\
\hline & & -15 & 420 & 19 & 441 \\
\hline & & -20 & 382 & 18 & 433 \\
\hline & \multirow{6}{*}{$5 \%$} & 5 & 186 & 24 & 312 \\
\hline & & 0 & 331 & 21 & 391 \\
\hline & & -5 & 361 & 19 & 446 \\
\hline & & -10 & 367 & 19 & 453 \\
\hline & & -15 & 432 & 19 & 573 \\
\hline & & -20 & 375 & 17 & 554 \\
\hline
\end{tabular}

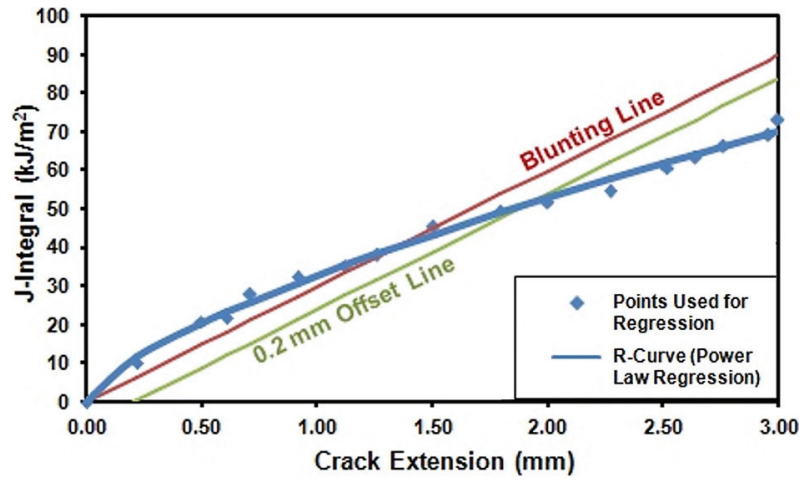

Fig. 12. Determination of the elastic-plastic fracture initiation toughness $\left(J_{I C}\right)$ for a type A mixture at $\mathrm{T}=+5{ }^{\circ} \mathrm{C}$, and a binder content of $4 \%$

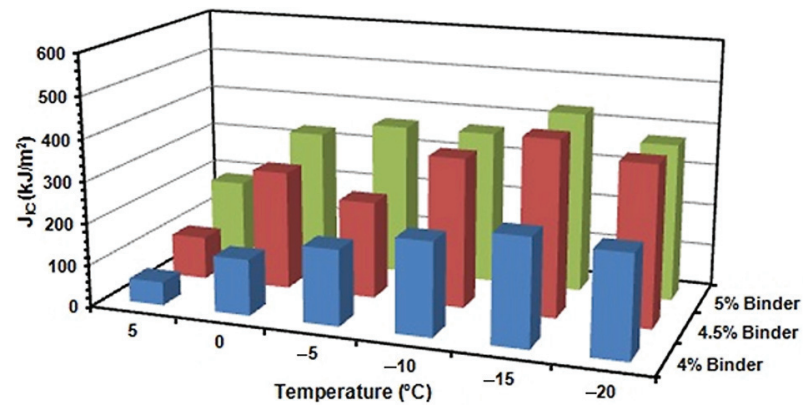

Fig. 13. Comparison histograms of fracture toughness values at six test temperatures and three binder contents for limestone asphalt concrete
Table 5. Fracture toughness and instability initiation J-integral values at six tested temperatures and three binder contents for siliceous asphalt concrete

\begin{tabular}{|c|c|c|c|c|c|}
\hline Mixture & $\begin{array}{c}\% \\
\text { Binder }\end{array}$ & $\begin{array}{l}\text { Temp. } \\
\left({ }^{\circ} \mathrm{C}\right)\end{array}$ & $\begin{array}{c}J_{I C} \\
\left(\mathrm{~kJ} / \mathrm{m}^{2}\right)\end{array}$ & $\begin{array}{c}a_{c r} \\
(\mathrm{~mm})\end{array}$ & $\begin{array}{c}J_{\text {instability }} \\
\left(\mathrm{kJ} / \mathrm{m}^{2}\right)\end{array}$ \\
\hline \multirow{18}{*}{ 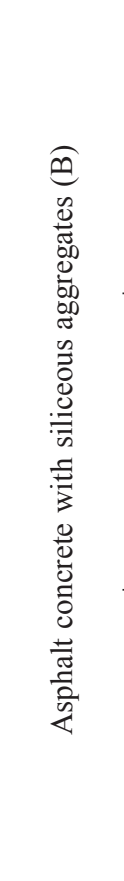 } & \multirow{6}{*}{$4 \%$} & 5 & 34 & 24 & 114 \\
\hline & & 0 & 77 & 22 & 145 \\
\hline & & -5 & 113 & 21 & 208 \\
\hline & & -10 & 154 & 20 & 232 \\
\hline & & -15 & 202 & 18 & 244 \\
\hline & & -20 & 194 & 17 & 271 \\
\hline & \multirow{6}{*}{$4.5 \%$} & 5 & 103 & 23 & 156 \\
\hline & & 0 & 174 & 20 & 233 \\
\hline & & -5 & 216 & 20 & 335 \\
\hline & & -10 & 227 & 18.5 & 308 \\
\hline & & -15 & 263 & 19 & 375 \\
\hline & & -20 & 255 & 18 & 373 \\
\hline & \multirow{6}{*}{$5 \%$} & 5 & 133 & 22 & 235 \\
\hline & & 0 & 207 & 19 & 262 \\
\hline & & -5 & 236 & 20 & 353 \\
\hline & & -10 & 254 & 18.5 & 376 \\
\hline & & -15 & 285 & 17 & 435 \\
\hline & & -20 & 263 & 17 & 412 \\
\hline
\end{tabular}

A comparison between the values of the fracture toughness for different test temperatures and different binder contents are presented in Figures 13 and 14. It can be seen that the fracture toughness for each binder content increases by reducing the temperature which is due to the rise in the binder toughness by the reduction of temperature and the strengthening of the bonds between the aggregates surface and the bitumen. The rise can be seen from $+5{ }^{\circ} \mathrm{C}$ to $-15{ }^{\circ} \mathrm{C}$. In this study, the fracture toughness is reduced below $-15^{\circ} \mathrm{C}$ for both limestone and siliceous mixtures as a result of the weakened bonding caused by pronounced difference between the coefficients of contraction between aggregates and the bitumen. The trend is also seen in the research by Kim and El Hussein (1997). Values of fracture toughness can be seen in Tables 4 and 5 .

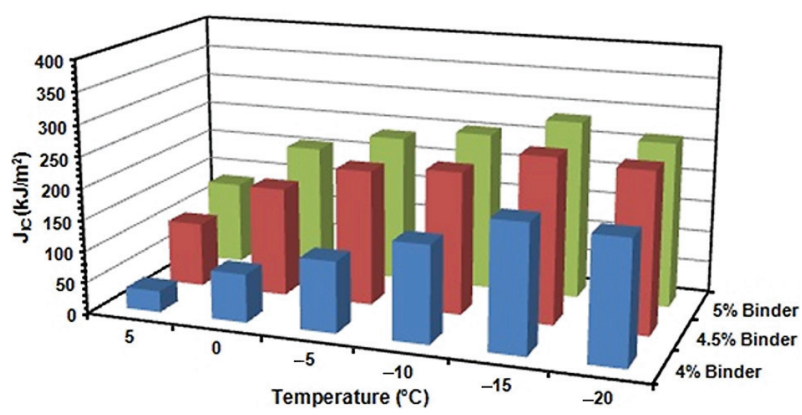

Fig. 14. Comparison histograms of fracture toughness values at six test temperatures and three binder contents for limestone asphalt concrete 


\section{Conclusions}

In this research, mode I low temperature fracture resistance of the HMA mixtures were investigated in terms of the R-curve behavior. A single specimen technique was implemented as detailed in the paper. The following conclusions can be made:

- Fracture resistance of the HMA increases with the increase in critical crack length - known as the length up to which crack growth is stable. The increase is temperature and binder content dependent. This can be assessed in terms of the R-curves.

- The critical crack length varies to a greater extent with temperature than with binder content. This crack length is decreased as the temperature is dropped.

- Reduction of temperature results in a further tendency of the mixture for unstable crack growth. This can be of serious concern in cracked pavement systems at temperatures below $-15^{\circ} \mathrm{C}$.

- Even though the modulus of the asphalt concrete is increased by reducing the temperature which is indicative of higher stiffness and better load bearing capacity, the crack growth resistance trend is not consistent. The mixture exhibits an improving crack growth resistance and fracture toughness up to $-15^{\circ} \mathrm{C}$ and starts to degrade thereafter in terms of fracture resistance.

- Loss of bond strength between the binder and the aggregate surface due to the embrittlement of the bitumen and the difference in the coefficients of thermal contraction of the two materials at lower temperatures causes a drop in fracture toughness.

\section{References}

Anderson, T. L. 2005. Fracture mechanics fundamentals and applications. $3^{\text {rd }}$ ed. New York: Taylor \& Francis. 621 p.

AASHTO T96-02 Standard method of test for resistance to degradation of small-size coarse aggregate by abrasion and impact in the Los Angeles machine. American Association of State and Highway Transportation Officials, USA, 2002. $3 \mathrm{p}$.

AASHTO T182-84 Standard method of test for coating and stripping of bitumen-aggregate mixtures. American Association of State and Highway Transportation Officials, USA, 2002. $6 \mathrm{p}$.

AASHTO T104-99 Standard method of test for soundness of aggregates by use of sodium sulfate or magnesium sulfate. American Association of State and Highway Transportation Officials, USA, 2003. 11 p.

ASTM D3202-2000. Standard practice for preparation of bituminous mixture beam specimens by means of the California Kneading compactor. American Society for Testing and Materials, USA, 2000. $3 \mathrm{p}$.

ASTM E1820-09 Standard test method for measurement of fracture toughness. American Society for Testing and Materials, USA, 2009. 56 p.

ASTM D3497-79(2003) Standard test method for dynamic modulus of asphalt mixtures. American Society for Testing and Materials, USA, 2003. 3 p.

ASTM E399-09 Standard test method for linear-elastic planestrain fracture toughness $K_{I c}$ of metallic materials. American Society for Testing and Materials, USA, 2009. 33 p.
ASTM D5821-13 Standard test method for determining the percentage of fractured particles in coarse aggregate. American Society for Testing and Materials, USA, 2013. 6 p.

Begley, J. A.; Landes, J. D. 1972. The J-integral as a fracture criterion, in Fracture Toughness, Proc. of the $1972 \mathrm{Na}$ tional Symposium on Fracture Mechanics. ASTM STP: $1-23$.

Braham, A.; Buttlar, W.; Marasteanu, M. 2007. Effect of binder type, aggregate, and mixture composition on fracture energy of hot-mix asphalt in cold climates, Journal of Transportation Research Board 2001: 102-109. http://dx.doi.org/10.3141/2001-12

BS 812-103.1 Testing aggregates - method for determination of particle size distribution. London: British Standards Institution, UK, 1985. 8 p.

Dongre, R.; Sharma, M. G.; Anderson, D. A. 1989. Development of fracture criterion for asphalt mixes at low temperatures, Journal of Transportation Research Board 1228: 94-105.

Ernst, H. A.; Paris, P. C.; Landes, J. D. 1981. Estimations on J-integral and tearing modulus $T$ from a single specimen test record, in Fracture Toughness, Proc. of the $1981 \mathrm{Na}$ tional Symposium on Fracture Mechanics. ASTM STP 743: 476-502.

Iran Highway Asphalt Paving Code. 2011. Ministry of Road and Transportation, Research and Education Center, Iran, No. 234. 263 p.

ISO 12135:2002 Metallic materials - unified method of test for the determination of quasistatic fracture toughness. Geneva: International Organization for Standardization, 2002. 94 p.

Kim, K. W.; El Hussein, M. 1997. Variation of fracture toughness of asphalt concrete under low temperatures, Construction and Building Materials 11(7-8): 403-411. http://dx.doi.org/10.1016/S0950-0618(97)00030-5

Landes, J. D. 2007. Evaluation of the ISO J initiation procedure using the EURO fracture toughness test data set, International Journal of Fracture 145(4): 285-297. http://dx.doi.org/10.1007/s10704-007-9118-x

Landes, J. D.; Begley, J. A. 1972. The effect of specimen geometry on $\mathrm{J}_{\mathrm{IC}}$, in Fracture Toughness, Proc. of the $1971 \mathrm{Na}$ tional Symposium on Fracture Mechanics. Part II, ASTM STP 514: 24-39.

Li, X.; Marasteanu, M. 2010. The fracture process zone in asphalt mixture at low temperature, Engineering Fracture Mechanics 77(7): 1175-1190. http://dx.doi.org/10.1016/j.engfracmech.2010.02.018

Marasteanu, M.; Labuz, J. F.; Dai, S. 2002. Determining the low-temperature fracture toughness of asphalt mixtures, Journal of Transportation Research Board 1789: 191199. http://dx.doi.org/10.3141/1789-21

Mobasher, B.; Mamlouk, M. S.; Lin, H. M. 1997. Evaluation of crack propagation properties of asphalt mixtures, Journal of Transportation Engineering 123(5): 405-413.

http://dx.doi.org/10.1061/(ASCE)0733-947X(1997)123:5(405)

Reis, J. M. L.; Chianelli, J. R.; Cardoso, J. L.; Marinho, F. J. V. 2011. Effect of recycled PET in fracture mechanics of polymer mortar, Construction and Building Materials 25(6): 2799-2804. http://dx.doi.org/10.1016/j.conbuildmat.2010.12.056

Rice, J. R. 1968. A path independent integral and the approximate analysis of strain concentration by notches and cracks, Journal of Applied Mechanics 35(2): 379-386. http://dx.doi.org/10.1115/1.3601206

University of Wisconsin-Madison. 2010. Investigation of low temperature cracking in asphalt pavements. National Pooled Fund Study - Phase II. Wisconsin, USA. 338 p.

Wagoner, M.; Buttlar, W.; Paulino, G. 2005. Development of a single-edge notched beam test for asphalt concrete mixtures, Journal of Testing and Evaluation 33(6): 1-9. 
Zhu, X. K.; Joyce, J. A. 2007. J-Resistance curve testing of HY80 steel using SE(B) specimens and normalization method, Engineering Fracture Mechanics 74(14): 22632281.

http://dx.doi.org/10.1016/j.engfracmech.2006.10.018

Zhu, X.-K.; Joyce, J. A. 2009. More accurate approximation of J-integral equation for evaluating fracture resistance curves, Journal of ASTM International 7(1): 90-115.
Zhu, X.-K.; Joyce, J. A. 2012. Review of fracture toughness (G, K, J, CTOD, CTOA) testing and standardization, Engineering Fracture Mechanics 85: 1-46. http://dx.doi.org/10.1016/j.engfracmech.2012.02.001

Zhu, X.-K.; Leis, B. N.; Joyce, J. A. 2008. Experimental estimation of J-R curves from load-CMOD record for $\mathrm{SE}(\mathrm{B})$ specimens, Journal of ASTM International 5(5): 66-86. http://dx.doi.org/10.1520/JAI101532

Sepehr GHAFARI. Received PhD degree in civil engineering from the Department of Civil and Environmental Engineering in Amirkabir University of Technology (Tehran Polytechnic) in 2013. He has been a teaching assistant for highway engineering and design as well as pavement engineering courses at the department of civil and environmental engineering in Amirkabir (Polytechnic) university from 2006 until 2013 and an assistant professor at Tehran Shahid Rajaee University from 2010 until now. He completed his Masters degree at Tehran Amirkabir (Polytechnic) university in highway engineering as well and had been in charge of the analysis and design of pavement systems, geotechnical structures, deep and shallow foundations at PASAR consulting engineers from 2007 until 2013. He is currently a project manager at NAVROOD Co., a leading civil construction contractor in Iran.

Fereidoon MOGHADAS NEJAD. Dr, is currently the consultant for Iran Road Maintenance and Transportation Organization and an associate professor at the Department of Civil and Environmental Engineering in Tehran Amirkabir University of Technology (Tehran Polytechnic). He completed his undergraduate education at Iran University of Science and Technology, where he received BSc. degree in civil engineering. He received his doctoral degree from the University of Sydney, Australia in 1997 followed by a one year post doctoral position researching on numerical modelling of the behaviour of Geosynthetics in pavements. His thesis discussed Geogrid reinforcement of pavements using experimental and numerical analyses. He has numerous articles and book chapters. 